\title{
Clustering of Multiple Chronic Disease Risk Behaviors among Middle School Youth
}

\author{
Karly S Geller*, Kristen Welker, Rebecca Williams and Grace B Tigue \\ Associate Professor, Miami University, USA
}

Received: June 22, 2018; Published: June 27, 2018

*Corresponding author: Karly S Geller, Associate Professor, Miami University, 420 S. Oak Street, 214 Phillips Hall, Oxford OH, 45056, USA

Abbreviations: PA: Physical Inactivity; TV: Television; FVC: Fruit and Vegetable Consumption; SMK: Cigarette Smoking; SMKL: Smokeless Tobacco; ALC: Alcohol

\section{Introduction}

Health-risk behaviors cluster or co-occur among youth populations [1-3], leading to increased risk for overweight/obesity and related chronic illnesses [4]. However, evidence specific to middle-school aged youth remains limited. In the current study the prevalence of multiple risk behaviors among middle-school aged youth are described and examined for co-occurrence. Outcomes are expected to inform the development of future research and intervention efforts among similar youth populations.

\section{Methodology}

Youth were recruited from health classrooms through teacher partnerships. All study procedures were approved by the University Institutional Review Board. Participating youth were asked to complete a 10 to 15 -minute paper-and-pencil questionnaire asking about their multiple health behavior, including their weekly physical activity, daily television viewing time, daily fruit and vegetable servings, alcohol use, cigarette use, and smokeless tobacco use. Youth also self-reported their age, gender, height and weight (calculated to body mass index (BMI), adjusting for age and gender). Classroom teachers reported class-level ethnicity and grade-level. Based on guidelines recommending youth perform at least $60 \mathrm{~min}$ utes of daily physical activity [5] youth were asked to report the number of days they perform 60 minutes of physical activity during a typical week. Those reporting less than 7 days a week of 60 minutes of physical activity were determined at-risk for physical inactivity. Daily television was also reported; youth reporting more than two hours per day were considered at-risk. Youth also reported their daily fruit and vegetable consumption, and those reporting less than 5 servings of fruit and vegetables were considered at-risk. Finally, youth who reported previously trying alcohol, cigarettes, and/or smokeless tobacco were considered at-risk.

\section{Statistical Analysis}

Risk for each health behaviors were described, as well as the prevalence of multiple health-risk behavior. Observed to expected ratio method (i.e., $0 / E>1$ ) was used to test significant clustering of behavioral risk factors with $95 \%$ confidence intervals. A larger observed value indicated that behavioral clustering among the examined risk behaviors was more likely to occur than any one singular risk behavior [1].

\section{Results}

Participating children were $7^{\text {th }}(95 \%)$ and $8^{\text {th }}(5 \%)$ grade middle school students ( $\mathrm{n}=105)$ from two schools in Ohio $(25 \%)$ and Indiana (75\%). Children included in analyses were predominantly Caucasian (>95\%), 50\% female, and 39\% were overweight/obese. Table 1 illustrates health risk percentages by gender. Physical inactivity was the most common risk behavior (61\% of youth), followed by inadequate fruit/vegetable consumption (38\%), excessive sedentary behavior (33\%), having ever tried alcohol (28\%), having ever tried smoking $(20 \%)$ and having ever tried smokeless tobacco (6\%). Relative to multiple health behavior, $15 \%$ of youth reported no risk behaviors, $28 \%$ reported one, $26 \%$ reported two, $21 \%$ reported three, $10 \%$ reported four, $1 \%$ reported five, and no youth reported all six risk behaviors. Table 1 contains multiple health risk with $0 /$ E ratios over 1 , including 16 risk behavior clusters, and three statistically significant clusters.

Having previously tried alcohol clustered most frequently (11 of the 16 clusters), followed by physical inactivity (10 clusters), and the combination of low fruit/vegetable consumption and having tried smoking (8 clusters). Clusters of three risk behaviors occurred most frequently (7 clusters), followed by four risk factors 
(5 clusters). Significant multiple behavior clusters included physical inactivity and excessive television $(\mathrm{O} / \mathrm{E}=1.28 ; 95 \% \mathrm{CI}=0.47$, $2.08)$, physical inactivity and low fruit/vegetable consumption $(\mathrm{O} /$ $\mathrm{E}=1.20 ; 95 \% \mathrm{CI}=0.48,1.92)$, and physical inactivity, low fruit/vegetable consumption, and having tried alcohol $(\mathrm{O} / \mathrm{E}=1.88 ; 95 \% \mathrm{CI}=$ $0.40,3.36)$.

Table 1: Clustering patterns of multiple behavior risk.

\begin{tabular}{|c|c|c|c|}
\hline Risks & Behavioral Cluster & $\begin{array}{c}\text { O/E } \\
\text { Ratio }\end{array}$ & $\begin{array}{c}\text { Confidence Interval } \\
\text { (95\%) }\end{array}$ \\
\hline 2 & PA_TV^ $^{\wedge}$ & 1.28 & $0.47,2.08$ \\
\hline 2 & PA_FVC^ & 1.20 & $0.48,1.92$ \\
\hline 2 & FVC_SMKL & 3.00 & $-2.95,8.95$ \\
\hline 3 & PA_FVC_ALC^ & 1.88 & $0.40,3.36$ \\
\hline 3 & PA_SMK_SMKL & 4.63 & $-4.64,14.06$ \\
\hline 3 & PA_SMK_ALC & 1.51 & $-0.60,3.62$ \\
\hline 3 & TV_FVC_SMK & 3.08 & $-1.23,7.41$ \\
\hline 3 & TV_SMK_ALC & 4.74 & $-1.87,11.30$ \\
\hline 3 & TV_SMKL_ALC & 9.22 & $-8.86,26.86$ \\
\hline 3 & FVC_SMK_ALC & 2.01 & $-1.99,6.03$ \\
\hline 4 & PA_TV_FVC_ALC & 1.88 & $-0.25,4.01$ \\
\hline 4 & PA_TV_SMK_ALC & 4.55 & $-0.61,9.75$ \\
\hline 4 & PA_FVC_SMK_ALC & 1.28 & $-1.27,3.83$ \\
\hline 4 & PA_SMK_SMKL_ALC & 24.16 & $-9.80,59.30$ \\
\hline 4 & TV_SMK_SMKL_ALC & 37.84 & $-32.47,98.48$ \\
\hline 5 & PA_TV_FVC_SMK_ALC & 2.57 & $-2.50,7.58$ \\
\hline
\end{tabular}

\section{Discussion}

The current study investigated the prevalence multiple health risk behaviors among middle-school aged youth, examining risk behaviors singularly and clusters. To date, few studies have examined the prevalence of multiple risk behaviors among middle-school aged populations. Although direct research comparisons are limited, current results are similar to previous risk health behaviors examinations among youth. Lawlor and colleagues [6] examined multiple risk behaviors among 14 year olds in Australia. Results showed $15 \%$ of youth reported having previously tried tobacco smoking, which is comparable to the $20 \%$ found in the current study. Researchers also reported close to $36 \%$ of adolescents watched television excessively television ( $>5$ hours per day; 3 ), which is similar to the $33 \%$ of youth in the current sample. Alamian and Paradis [1] examined multiple risk behaviors among Canadian children (10 to 17 years old), including physical inactivity, sedentary behavior, tobacco smoking, alcohol use, and overweight/obesity.

The prevalence of multiple risk behaviors reported were slightly higher than the middle school-aged children in the current study. Specifically, Alamian and Paradis [1] reported $65 \%$ of youth prac- ticed two or more risk behaviors (compared to $57 \%$ of children in the current study) and 37\% reported three or more (compared to the current $32 \%$ ). Noteworthy is the larger proportion of overweight/obese children in the current study (39\%) compared to $25 \%$ of youth reported by Alamian and Paradis [1]. Disparate from Alamian and Paradis [1], the current analysis did not include overweight/obese as a behavioral risk factor and may explain the proportion differences observed.

\section{Conclusion}

Certain limitations and strengths of the current study are notable. First, the current study included a relatively small sample size $(n=105)$, limiting generalizability. On the other hand, multiple health behavior examinations among similarly aged youth are limited to date. The unstandardized measurement of health behaviors across studies is a second limitation, preventing direct comparison of current outcomes. To further expand on current outcomes, additional research among middle school-aged children using larger, more representative sample is warranted. Additionally, future research should evaluate potential social and environmental interactions contributing to the occurrence and co-occurrence of multiple risk behaviors.

\section{Acknowledgement}

This research was funded by the Committee on Faculty Research, Office of Advancement of Research \&amp; Scholarship (OARS) at Miami University, Ohio.

\section{References}

1. Alamian A, Paradis G (2009) Clustering of chronic disease behavioral risk factors in Canadian children and adolescents. Preventive Medicine 48(5): 493-499.

2. Lowry R, Wechsler H, Galuska D, Fulton J, Kann L (2002) Television viewing and its associations with overweight, sedentary lifestyle, and insufficient consumption of fruits and vegetables among US high school students: differences by race, ethnicity, and gender. Journal of School Health, 72(10): 413-421.

3. Spring B, Moller A, Coons MJ (2012) Multiple health behaviors: overview and implications. Journal of Public Health 34(suppl1): i3-i10.

4. Berrigan D, Dodd K, Troiano R, Krebs-Smith, SR Barbash (2003) Patterns of health behavior in U.S. adults. Preventive Medicine: An International Journal Devoted to Practice and Theory 36(5): 615-623.

5. Strong W, Malina R, Trudeau F (2005) Evidence based physical activity for school-age youth. Journal of Pediatrics, 146(6): 732-737.

6. Lawlor D, Ocallaghan M, Mamun A, Williams G, Bor W, et al. (2005) Socioeconomic position, cognitive function, and clustering of cardiovascular risk factors in adolescence: findings from the Mater University Study of Pregnancy and its outcomes. Psychosomatic Medicine 67(6): 862-868. 
(c) (i) This work is licensed under Creative Submission Link: https://biomedres.us/submit-manuscript.php

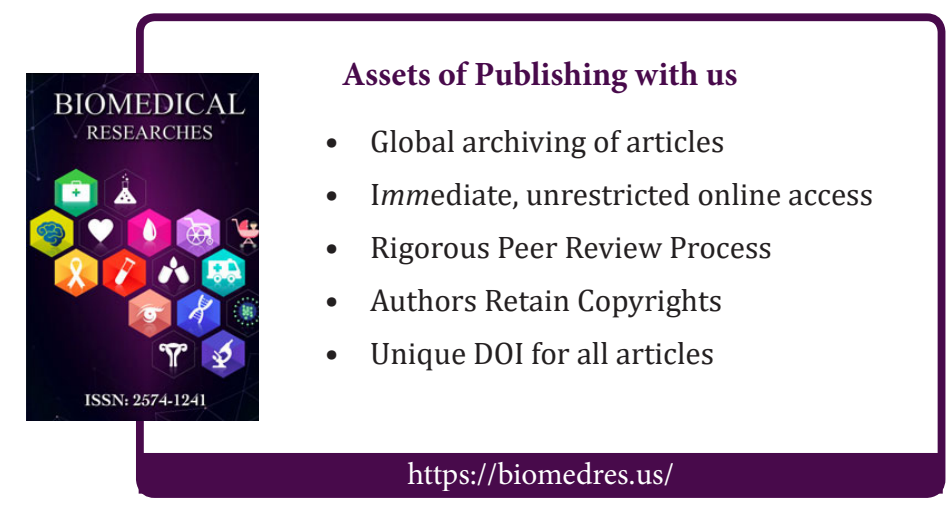

